\title{
Hare today, gone tomorrow: the role of interspecific competition in shaping riverine rabbit occurrence
}

\author{
Zoë Woodgate $^{1, *}$, Greg Distiller $^{2}$, M. Justin O'Riain ${ }^{1}$ \\ ${ }^{1}$ Institute for Communities and Wildlife in Africa, Department of Biological Sciences, University of Cape Town, \\ Cape Town 7701, South Africa \\ ${ }^{2}$ Statistics in Ecology, Environment and Conservation, Department of Statistical Science, University of Cape Town, \\ Cape Town 7701, South Africa
}

\begin{abstract}
Effective conservation, particularly of threatened species, requires an understanding of both abiotic and biotic drivers of distribution. In the case of one of Africa's most endangered mammals, the riverine rabbit Bunolagus monticularis, only environmental covariates of presence have been used to provide coarse predictions of their distribution. Two potential competitors, namely scrub hare Lepus saxatilis and cape hare L. capensis, have significant (>90\%) range overlap with the riverine rabbit, yet little is known about how these species interact. We used multispecies occupancy models, which model co-occurrence as a function of environmental variables, to assess the spatial response of riverine rabbits to both species of hare in Sanbona Wildlife Reserve, South Africa. We also examined temporal overlap between riverine rabbits and hares. Camera trapping data were collected from 150 camera traps distributed in clusters of 5 cameras at 30 independent sites, covering $223.24 \mathrm{~km}^{2}$. Contrary to prior studies, we found that riverine rabbits were not restricted to riparian habitat, and that their occurrence was conditional on hare absence and was negatively affected by terrain ruggedness. Whilst hare occurrence was independent of terrain ruggedness, it was negatively affected by rabbit presence. Activity patterns revealed high temporal overlap between hares and rabbits $(\Delta=0.828, \mathrm{CI}=0.745-0.940)$; however, neither species co-occurred at any given site. Our results suggest that conservation management has greatly underestimated the importance of competition with other lagomorphs in understanding riverine rabbit occurrence.
\end{abstract}

KEY WORDS: Riverine rabbit · Endangered species $\cdot$ Camera trapping $\cdot$ Multi-species occupancy · Interspecific competition

\section{INTRODUCTION}

Understanding factors that influence the distribution of species is critical to their conservation (Marcer et al. 2013, Burgar et al. 2019). Biotic variables including interspecific competition are important (Connell 1983, Akçakaya et al. 2020), but they are more difficult to quantify and are thus often overlooked by conservation management in favour of defining suitable habitat in terms of easily measured

\footnotetext{
*Corresponding author: zwoodgate@outlook.com
}

environmental attributes (Campbell et al. 2002). Mitigation strategies which ignore biotic interactions may present recovery criteria that are not biologically meaningful, hindering efforts intended to contribute to the persistence of threatened species (Dee Boersma et al. 2001, Campbell et al. 2002, Gerber \& Hatch 2002, Akçakaya et al. 2020).

The riverine rabbit Bunolagus monticularis is one of the rarest wild animals in Africa, and it is currently listed as Critically Endangered under IUCN Red List

() The authors 2021. Open Access under Creative Commons by Attribution Licence. Use, distribution and reproduction are unrestricted. Authors and original publication must be credited. 
criteria (Collins \& du Toit 2016). Having recently disappeared from several known localities, conservationists suggest that its numbers are declining (Ahlmann et al. 2000). Despite this concern and their rarity, only 3 studies, each conducted at a single locality, have attempted to understand the environmental covariates associated with the species' presence (Duthie 1989, Coetzee 1994, Adams 2014). All 3 studies have proposed that the riverine rabbit is a habitat specialist, dependent on the soft alluvial soils and vegetation along seasonal water courses in the semi-arid regions of the Groot and Klein Karoo, South Africa. These riverine corridors are used extensively by farmers for small-scale cultivation of feed crops and for grazing livestock (Collins \& du Toit 2016). Such agricultural activities are assumed to have adversely impacted riparian habitat, driving the decline of riverine rabbits (Duthie 1989, Hughes et al. 2008). Endeavours to preserve such habitat, such as establishing conservancies along important drainage lines, have thus been at the vanguard of recent conservation efforts (Smith et al. 2018, Ahlmann et al. 2000).

Recently, Collins \& du Toit (2016) utilised data from direct observations and museum records, within a Maxent modelling framework, to derive a predictive distribution map and estimate the total population size of the species. However, using presence-only data to build species distribution models often introduces a sampling bias that is difficult to overcome (Tobler et al. 2019). Collins \& du Toit (2016) conceded that their models failed to produce reliable results for 1 subpopulation, and that no single model performed well across the species' known range. Additionally, new localities of the species have been confirmed well outside of their predicted distribution and seldom in what was considered to be their preferred habitat.

Species distribution models have improved inference about the habitat associations of species when biological interactions are included (Burgar et al. 2019). Whilst the mechanism of competitive exclusion between lagomorphs (particularly between Lepus species) remains largely unknown, there is evidence that it plays a significant role in shaping their distributions (Hulbert et al. 1996, Probert \& Litvaitis 1996, Leach et al. 2017). Weak competitive interactions often lead to resource partitioning, allowing multiple species to occur within the same landscape (Connell 1983, Amarasekare 2003, Araújo \& Luoto 2007, Lush et al. 2017). Alternatively, temporal avoidance may facilitate coexistence (Stott 2003). However, during periods of food scarcity and/or when competitors are phylogenetically closely related (Valiente-Banuet \& Verdú 2008), this cooccurrence may lead to local exclusion (Amarasekare 2003). Despite its importance, research on threatened lagomorphs rarely includes the influence of sympatric competitors from the same order (Scharine et al. 2011, Lorenzo et al. 2015).

A number of larger lagomorph species have significant $(>90 \%$ ) range overlap with the riverine rabbit, namely scrub hare Lepus saxatilis, cape hare $L$. capensis and, to a lesser degree, Smith's red rock hare Pronolagus rupestris (Farmer 2006). There is some evidence of dietary overlap among all 4 species (Duthie 1989, Kerley 1990). Species from the Aizoaceae family (commonly referred to as 'vygies') and the Bassia genera make up the bulk of the riverine rabbit diet in the drylands of South Africa (Duthie 1989, Hughes et al. 2008). Similarly, hares (which are mixed feeders) have been known to browse on both grasses and species from the Aizoaceae (Kerley 1990), although their feeding habits appear to vary across their range (Robinson et al. 2016). Duthie (1989) noted that there may indeed be competitive interactions between riverine rabbits and scrub hares, but was unable to provide evidence for his suggestion or infer which was the more dominant competitor.

Camera traps have emerged as a useful tool for gathering data on rare and elusive species and provide useful information on the presence and absence of competitors (Fidino et al. 2019). They have also been used to successfully study lagomorphs (Arias Del-Razo et al. 2012, Caravaggi et al. 2016, Tilker et al. 2020), and Adams (2014) demonstrated the potential of camera trapping as a monitoring technique for the riverine rabbit. Camera trap data is commonly used in assessing interspecific competition by calculating daily activity overlap (Chaudhary et al. 2020) and co-occurrence (Devarajan et al. 2020). Recent statistical advances allow for modelling the co-occurrence of multiple species as a function of environmental covariates (Rota et al. 2016). Such models allow ecologists to investigate hypotheses relating to the role of interspecific competition in habitat selection and spatial distribution (Rota et al. 2016, Ladle et al. 2018, Parsons et al. 2018).

In this study, we used camera trapping data from Sanbona Wildlife Reserve (SWR), South Africa, to investigate the importance of interspecific interactions between riverine rabbits and hares along environmental gradients. It is impossible to distinguish between the ecologically similar scrub and cape hare from camera trap photographs, so captures of both 
species were classified as 'hare' and treated as 1 species in the analyses. We hypothesised that both riverine rabbit and hare would minimise the risk of negative interactions through temporal and spatial avoidance. We predicted that both species would spatially segregate along local habitat covariates, but temporally segregate when co-occurring. We tested this hypothesis by estimating the activity patterns and subsequent overlap of both species (Ridout \& Linkie 2009) and then applying a multi-species occupancy model (Rota et al. 2016) to investigate changes in the co-occurrence of riverine rabbits and hares with select environmental variables.

\section{MATERIALS AND METHODS}

\subsection{Study area}

The study was conducted in the SWR (Fig. 1). At $550 \mathrm{~km}^{2}$, this is the largest private nature reserve in the Western Cape, South Africa, and was established in 2002 following the merging of 19 privately owned farms (Swanepoel 2019). All domestic livestock were removed prior to the merge, and large indigenous ungulates were reintroduced in 2003 together with selected extra-limital species. The reserve is roughly bisected by the Warmwaterberg Mountain and an impermeable game fence, with the northern section receiving less rainfall (mean annual $=150 \mathrm{~mm}$ ) than the southern section $(300 \mathrm{~mm})$. The northern section

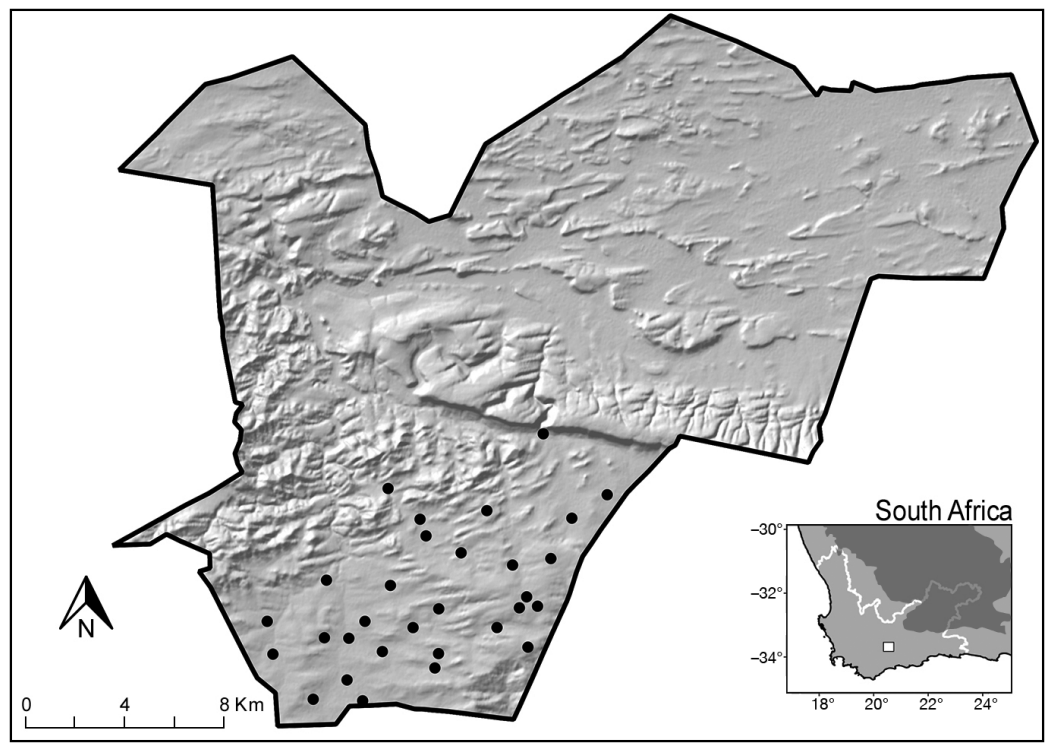

Fig. 1. Study area (Sanbona Wildlife Reserve) overlaid on a digital elevation map with hillshade. Black dots: locations of all 30 camera sites (each dot represents a cluster of 5 camera traps). Insert: location of the study area in relation to the Western Cape province, South Africa; dark gray area represents the Nama Karoo is dominated by semi-arid succulent karoo vegetation, while critically endangered renosterveld vegetation is found across the southern section (Swanepoel 2019). Riverine habitats, found in and around major drainage lines, are present throughout the reserve. These broad vegetation types greatly influence the distribution of megaherbivores within the reserve (Swanepoel 2019).

For the purposes of this study, we confined the survey to the southern section of the reserve (central coordinates: $33.823698^{\circ} \mathrm{S}, 20.595015^{\circ} \mathrm{E}$ ), where there had been previous opportunistic sightings of riverine rabbits. This section covers an area of approximately $126.89 \mathrm{~km}^{2}$ and includes all 4 of the dominant vegetation types present in the reserve.

\subsection{Camera trapping}

We used camera traps (Bushnell Trophy 2012 CAM $\mathrm{HD}$ ) to survey for riverine rabbits and hares. As single-camera trap survey designs are known to detrimentally impact occupancy estimates (O'Connor et al. 2017, Evans et al. 2019) and given the scarcity of our target species, we decided to place camera traps in clusters of 5 non-independent cameras, with each cluster covering an area equivalent to the estimated home range of riverine rabbits $\left(0.15 \mathrm{~km}^{2}\right.$; Duthie 1989). Clusters (hereafter called 'sites') were selected using a random stratified design across the 4 main habitat types present in the southern section of the SWR (renosterveld, riverine, thicket and succulent karoo). Cameras were placed randomly within sites. This resulted in a total of 30 sites (150 camera traps) with an average distance of $4.63 \mathrm{~km}$ between neighbouring sites (minimum of $1 \mathrm{~km}$ between each site; Fig.1).

Cameras were mounted on steel stakes at a height of approximately $30 \mathrm{~cm}$ above the ground. To minimise false triggers, vegetation was removed within the detection range of each camera. A 30 s delay was programmed between successive photographs and the sensor set to high sensitivity. All cameras within a site were operational for 45 consecutive days, but not all sites were sampled simultaneously, with camera traps being rolled over in 3 phases between the end of April and end of November 
2015. SD cards were only retrieved from cameras at the end of each phase to minimise human disturbance in the study area. We catalogued all independent captures per site (defined by 30 min intervals between photographs of the same species or if the capture was clearly of a new individual) using Camera Base ${ }^{\circledR}$ software (Tobler 2014).

\subsection{Temporal overlap}

To investigate overlap in the temporal activity between riverine rabbits and hares, we extracted time-stamps from all independent captures of each species. These markers were used to create distributions of photographic captures across $24 \mathrm{~h}$ periods. The coefficient of overlap $(\Delta)$ was estimated using non-parametric methods, as developed by Ridout \& Linkie (2009), to account for small sample sizes $(<75)$ (Meredith \& Ridout 2016). The value of $\Delta$ can range from $0-1$, where 1 represents complete temporal overlap in activity for both riverine rabbit and hare. Subsequent confidence intervals were calculated from 500 bootstrap samples. Temporal overlap was calculated using the R package 'overlap' (Meredith \& Ridout 2016) in R v.4.0.0 (R Core Team 2020).

\subsection{Co-occurrence modelling}

We applied a multi-species occupancy model developed by Rota et al. (2016) to investigate the occupancy of both riverine rabbit and hare species in the SWR. As our survey design only accounted for known riverine rabbit home range size and not the data deficient hare, model estimates in our study are more analogous to occurrence (or 'use') than true occupancy (Gould et al. 2019, Parsons et al. 2019). In our model, which is a generalisation of MacKenzie et al.'s (2002) single-species occupancy model, the latent occupancy state $(\psi)$ is assumed to be a multivariate Bernoulli (MVB) random variable. Therefore, when there are 2 species:

$$
Z \sim \operatorname{MVB}\left(\psi_{11}, \psi_{10}, \psi_{01}, \psi_{00}\right)
$$

where $Z$ is a 2-dimensional vector of 1 s and 0 s designating the latent occurrence state of species $i$ and $j$, such that $\psi_{11}$ represents presence of both species, $\psi_{00}$ absence of both species and $\psi_{10} / \psi_{01}$ represents presence of only species $i$ or only species $j$, respectively. . As an MVB distribution generalises the Bernoulli distribution to $>1$ dimension, no a priori assumptions about asymmetric species interactions are required, thereby overcoming the limitations of previous 2-species conditional occupancy models. This allows researchers to explore different hypotheses regarding the influence of environmental covariates and species interactions (Rota et al. 2016, Devarajan et al. 2020).

To investigate the importance of interspecific interactions, we constructed 2 sets of models which, following Miller et al. (2018), were analysed together as part of an integrated modelling framework (Rota et al. 2016). The first set comprised marginal occurrence models which assumed that riverine rabbits and hares occur independently. The second set comprised conditional occurrence models that assumed the occurrence probability of both species was dependent on the presence or absence of one another. This second set of models included structures that allowed the conditional occurrence probability to change as a function of environmental covariates.

All models were fitted in STAN v.2.23 (Stan Development Team 2020) using the 'rstan' v.2.19.3 interface. Four chains were run for each model, and trace plots were used to determine an adequate burn-in phase. As we lacked prior information on the relationship between rabbit and hare co-occurrence and the selected environmental covariates, we set uninformed logistic priors for all parameters. All models achieved adequate convergence by running 50000 iterations following a burn-in phase of 25000 iterations. We assessed model fit with the Brooks-Gelman-Rubin convergence diagnostic $(\hat{R}=1.1$; Gelman et al. 2014) and visually examined the posterior distributions via trace plots (Rota et al. 2016, Conn et al. 2018, Kass et al. 2020). Models were ranked using Watanabe-Akaike's information criterion (WAIC), which is appropriate in measuring the fit of Bayesian models (Gelman et al. 2014). Models with a $\Delta$ WAIC < 2 were considered equally plausible.

\subsection{Covariates}

We modelled variation in occurrence using 5 covariates previously assessed as being important for lagomorphs in the drylands of South Africa. All covariates were calculated at the site level either using camera trap photographs or by extracted mean values for a $400 \mathrm{~m}^{2}$ buffer area around each site. The following methods were used to derive geospatial data. (1) distance to drainage: distance (m) from each site's centroid to the nearest drainage line (Swanepoel 2019) was determined using nearest-neighbour 
analysis. (2) Terrain ruggedness: $30 \mathrm{~m}$ raster elevation data from the Shuttle Radar Topography Mission (SRTM) (2008) was used to calculate a topographic ruggedness index as mean difference in elevation (m) between the central pixel and its 8 neighbours (Wilson et al. 2007). (3) Land degradation: the Modified Soil-Adjusted Vegetation Index (MSAVI2) (Qi et al. 1994) was used as a proxy for historical habitat degradation, similar to previous studies in drylands (Rossi et al. 2018). MSAVI2 is calculated with the following formula:

$$
\begin{aligned}
& \text { MSAVI2 }= \\
& \frac{2 \times \mathrm{NIR}+1-\sqrt{(2 \times \mathrm{NIR}+1)^{2}-8 \times(\mathrm{NIR}-\mathrm{RED})}}{2}
\end{aligned}
$$

where NIR is the near infrared band reflectance and RED is the red band reflectance from the ModerateResolution Imaging Spectroradiometer (MODIS) sensor (Didan et al. 2015). We averaged MSAVI2 for each site for the entire survey period. (4) Predator relative abundance: the number of independent photographs per 100 trap nights provided the relative abundance index (RAI) of 2 common predator species known to prey on leporids, namely the blackbacked jackal Canis mesomelas and caracal Caracal caracal (Drouilly et al. 2018b). (5) Vegetation type: we used the SANBI vegetation map of South Africa, Lesotho and Swaziland (Mucina et al. 2006) to extract the vegetation type for each $400 \mathrm{~m}^{2}$ site. The 4 vegetation types present in the study area included succulent karoo, renosterveld, thicket and drainage. If multiple types were present within a site, the dominant vegetation type ( $>50 \%$ coverage) was used.

Finally, 'Nuisance' covariates (i.e. longitude and latitude) were included in all models to account for spatial variation not directly related to our main hypotheses. We modelled detection probability using 1 covariate, namely vegetation type. Covariates were checked for correlation using Pearson correlation tests; none were highly correlated.

\section{RESULTS}

We recorded a total of 3794 detections of 31 mammal species $>0.5 \mathrm{~kg}$ during 1824 active camera nights (Table S1 in the Supplement at www.int-res.com/ articles/suppl/n044p351_supp.pdf). We captured 58 independent photographs of riverine rabbits at 5 sites (naïve occurrence: 0.17) and 114 independent photographs of hare species at 11 sites (naïve occurrence: 0.37 ); however, neither species co-occurred at any site.

\subsection{Temporal overlap}

The daily activity patterns of riverine rabbits and hares overlapped substantially $(\Delta=0.828, \mathrm{CI}=$ $0.745-0.940$; Fig. 2), where both species were crepuscular. Riverine rabbits had a slightly longer activity window, with no clear peak in activity. Hare activity peaked ca. 01:00-03:00 h and was suppressed during midday.

\subsection{Co-occurrence and covariates}

In total, 57 candidate models were considered in this study (Table S2). Model selection provided clear evidence for interspecific dependence between riverine rabbits and hares, where all marginal models were ranked considerably lower than the top conditional model ( $\triangle$ WAIC $\geq 4.041$ ). We found that our chosen detection covariate (vegetation type) failed to improve the model in all instances and was not included in the top 12 models. The top model (M1; WAIC weight $[w$ WAIC] $=0.2$ ) had a $\hat{R}$ value of 1.004 , indicating sufficient convergence. M1 retained only terrain ruggedness as an occurrence covariate (Table 1). The daily detection probability of riverine rabbits was similar to that of hares (riverine rabbit: $0.334, \mathrm{CI}=0.177-0.492$; hare: $0.326, \mathrm{CI}=0.161-$ 0.488 ), and both were notably low. The second highest ranked model $(\triangle \mathrm{WAIC}=2.352, w \mathrm{WAIC}=0.06)$ incorporated the predator RAI but not terrain ruggedness. Hereafter, we present results from our top ranked model, which had considerably more support than the next best model.

Riverine rabbits and hares showed strong negative co-occurrence $\left(f_{12}=-2.35\right)$, with neither species cooccurring at any given site. Irrespective of terrain ruggedness, there was a $90 \%$ reduction in the prob-

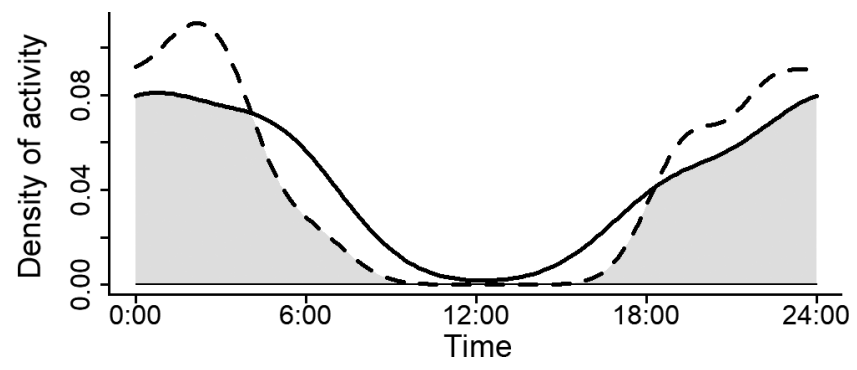

Fig. 2. Daily activity patterns of riverine rabbit Bunolagus monticularis (solid line) and hare spp. Lepus saxatilis and $L$. capensi (dashed line) in the Sanbona Wildlife Reserve, South Africa. Shaded area: temporal overlap between B. monticularis and Lepus spp. 
Table 1. Beta coefficients and $95 \%$ credible intervals for the top multi-species occurrence model. Estimates where the credible intervals did not overlap zero are highlighted in bold

\begin{tabular}{|c|c|c|c|c|c|c|c|c|c|}
\hline \multirow{2}{*}{ Parameter } & \multicolumn{3}{|c|}{ — Riverine rabbit -} & \multicolumn{3}{|c|}{ - Hare } & \multicolumn{3}{|c|}{ Riverine rabbit $\times$ Hare } \\
\hline & $\beta$ & Lower & Upper & $\beta$ & Lower & Upper & $\beta$ & Lower & Upper \\
\hline Intercept & -1.88 & -3.81 & -0.49 & -0.58 & -1.75 & 0.45 & -2.35 & -5.76 & -0.17 \\
\hline Terrain ruggedness & -1.94 & -3.83 & -0.45 & -0.42 & -1.39 & 0.53 & 0.68 & -1.68 & 3.23 \\
\hline
\end{tabular}

ability of occurrence for either species when the other was present. Terrain ruggedness, the only environmental covariate retained in our top model, adversely affected the marginal occurrence probability of both species (Fig. 3). However, its effect is

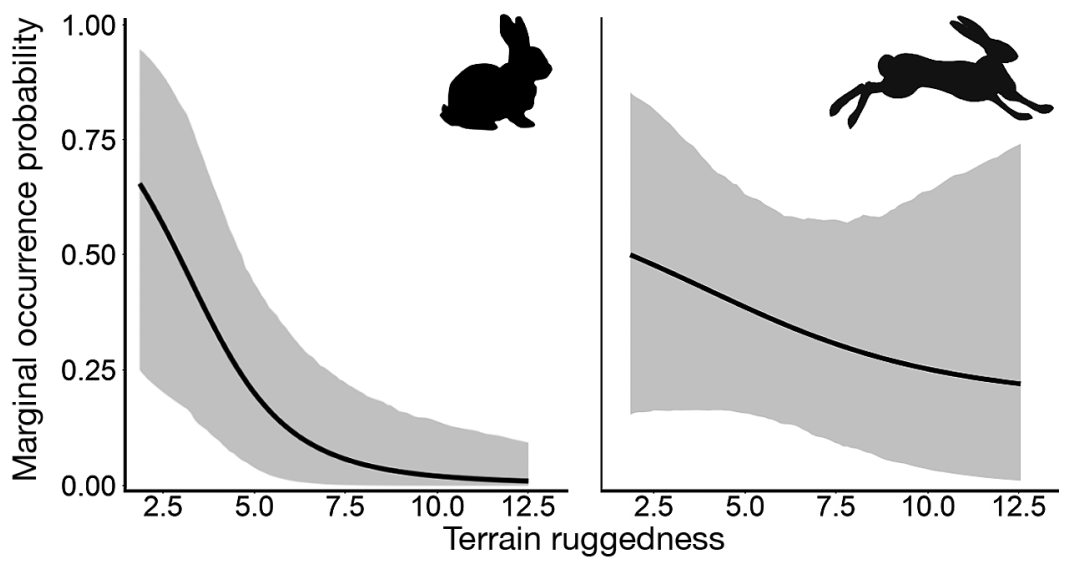

Fig. 3. Marginal occurrence probability of riverine rabbit Bunolagus monticularis and hare Lepus saxatilis and L. capensis, shown as a function of terrain ruggedness. Lines: posterior means; shading: $95 \%$ credible intervals. All variables not included in a plot are fixed at their observed means more nuanced than the marginal relationship suggests. Terrain ruggedness was only a strong driver for riverine rabbit conditional and marginal occurrence. Specifically, terrain ruggedness exerted a prominent negative influence on rabbit conditional occurrence, and was stronger at sites when hares were absent (Fig. 4). Conversely, terrain ruggedness was a weak driver of hare occurrence. It was still noted that a unit increase in ruggedness was associated with a $35 \%$ decrease in hare conditional occurrence probability when rabbits were absent, but a 30\% increase when rabbits were present (Fig. 4).

\section{DISCUSSION}

Our study is the first to account for interspecific interactions within a multi-species occupancy framework to determine the drivers of riverine rab-
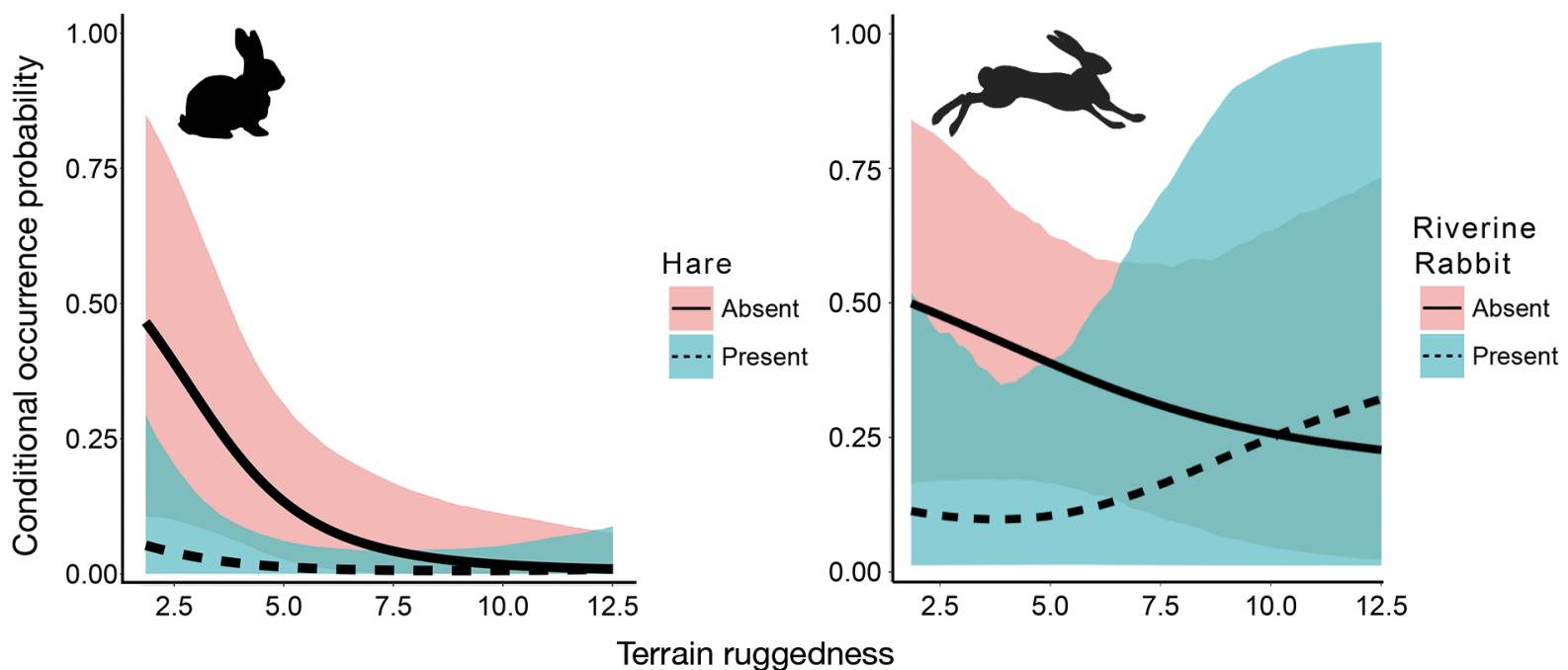

Fig. 4. Conditional occurrence probability of riverine rabbit Bunolagus monticularis (left) and hare spp. Lepus saxatilis and L. capensis (right), shown as a function of terrain ruggedness. Lines: posterior means; shading: $95 \%$ credible intervals, shaded according to presence/absence of the other species. All variables not included in a plot are fixed at their observed means 
bit distribution and the first to investigate the potential of temporal niche partioning between closely related lagomorph species in Africa. Despite research showing significant temporal partitioning between lagomorphs (Harrison 2019, Weterings et al. 2019) we found no evidence of temporal avoidance between rabbits and hares (Fig. 2). It is probable that thermoregulatory and antipredator strategies may be more important than competition between lagomorphs in the SWR (Larrucea \& Brussard 2009); however, as riverine rabbits and hares were not detected together at any site, we could not determine if either species altered their temporal niche when co-occurring. We suggest that further work should attempt to expand our camera trapping methodology across the drylands of South Africa to investigate this question further.

Our prediction that riverine rabbits and hares would spatially segregate to avoid direct competition was supported, as the top model predicted a near-zero co-occurrence. Globally, the geographic ranges of species from the Lepus genus often overlap or encompass those of rabbits (Scott 2003, Alves et al. 2008). This sympatry has been poorly understood and is often attributed to fine-scale segregation associated with preferential habitat selection (Chapman \& Flux 1990, Hulbert et al. 1996, Scharine et al. 2011). In our study, riverine rabbits and hares clearly segregated at the landscape level. The top co-occurrence model incorporated pairwise interactions between both riverine rabbits and hares, whilst retaining only one environmental covariate (terrain ruggedness), and it performed significantly better than all marginal models and models where species interactions did not vary along an environmental gradient (Table S2).

Riverine rabbits in the SWR were unlikely to occur at any sites where hares were present, regardless of how rugged the terrain was. It was only in the absence of hares that terrain ruggedness exerted a strong negative effect on riverine rabbit occurrence (Fig. 4), where rabbits favoured smoother topography commonly associated with fertile plains (Nunn \& Puga 2012). In contrast, the relationship between hare occurrence and terrain ruggedness changed dramatically depending on whether riverine rabbits were predicted to be present or not. Whilst not a strong effect, terrain ruggedness negatively impacted hare marginal and conditional occurrence when rabbits were absent, similar to other studies in which hares preferred the more open plains (Mayer et al. 2020). However, the model predicted that hares would favour slightly more rugged terrain should both species co-occur. This response suggests that both species of hare are able to change their habitat preferences when in the presence of their closely related competitor. Such fine-scale habitat selection has been documented amongst other lagomorph species (Hulbert et al. 1996, Scharine et al. 2011), allowing amicable co-existence at the landscape level.

As riverine rabbits have been previously associated with riparian habitat (Duthie 1989), we expected habitat or distance to drainage to be important in riverine rabbit occurrence. However, neither covariate was included in our top model ( $w$ WAIC $\leq$ 0.06; Table S2). Whilst Duthie (1989) and, to a lesser degree, Coetzee (1994), described the riverine rabbit as a riverine habitat specialist, the paucity of basic biological information on the species makes it difficult to evaluate this claim. Hughes et al. (2008) assumed that riverine rabbits did not appear to occupy areas of steep slope as a result of associated first and second order streams, which lack the alluvial soils supposedly preferred by rabbits. We suggest riverine rabbits may be restricted to the more fertile plains, and not third or fourth order rivers, whilst being unable to compete with the ecologically flexible hares who can use refugia present along a range of ruggedness (Smith et al. 2018). We acknowledge that because we worked at a novel site we cannot control for environmental factors when comparing our results with these previous studies. However, given the strong effect of competitive interactions on riverine rabbit occurrence in our system, we would urge caution when modelling their ecological association with solely abiotic predictors. Absence of modelled dependence between rabbits and hares in the Collins \& du Toit (2016) study may explain why their models did not perform well across the entirety of riverine rabbit range. Our results, together with recent studies showing the importance of interspecific competition on species distribution more generally (Leach et al. 2017, Tobler et al. 2019), justify a reassessment of riverine rabbit distribution using both abiotic and biotic variables.

Historical land degradation and predator RAI, 2 covariates shown to be important in determining lagomorph habitat selection (Havstad et al. 1999, Smith et al. 2005, Rouco et al. 2019), were not significant drivers of either riverine rabbit or hare occurrence in the SWR (whilst predator RAI was incorporated in the $2^{\text {nd }}$ ranked model, its $w$ WAIC was 0.06 and therefore not well supported; Table S2). It is possible that at the scale of our study, patterns in preda- 
tor RAI, most of which have home ranges far greater than our study area (Table S1, Drouilly et al. 2018a), were not apparent. Vegetation density and structure has been shown to be associated with habitat riskiness in other recent lagomorph studies (Weterings et al. 2019, Mayer et al. 2019, 2020), and it is therefore possible that riverine rabbits and hares prefer less rugged terrain that allows for the early detection of predators. However, several important predator species, such as Verreaux's eagle Aquila verreauxii, were excluded from our study as camera trapping is an unsuitable method for detecting such species. Weterings et al. (2019) used camera trapping to quantify residence time by hares, rabbits and foxes in the Netherlands, and found that hares were more strongly affected by habitat riskiness than rabbits. We suggest that future work on riverine rabbit and hare competition incorporate an analysis similar to that of Weterings et al. (2019) as well as attempt to devise methods to identify and then collect dung pellets to allow for dietary and genetic analyses.

Flexible habitat selection in the presence of a competitor, as shown by the hares in our study, has been shown to indicate subordination (Aunapuu \& Oksanen 2003). Indeed, Duthie (1989) noted that riverine rabbits did not co-occur with hares unless the former were at unusually low densities (less than $50 \%$ of other sites surveyed in the study). He hypothesized that high mortality rates in riverine rabbits allowed for the competitively excluded hare to extend their range into the former's preferred habitat of dense riparian vegetation. This interpretation is contrary to ours, and we would argue that the generalist nature of both hare species (Farmer 2006), their broader distribution (Robinson et al. 2016) and larger size (1.4-4.0 kg for hares versus $1.4-1.9 \mathrm{~kg}$ for riverine rabbits) all suggest that they competitively displace riverine rabbits in the SWR. Interestingly, our results are similar to those from studies conducted on islands, whereby introduced hares are far more antagonistic to rabbits and frequently extirpate them on islands smaller than 1000 ha (Alves et al. 2008, Flux 2008). It is possible that in resource-sparse environments, such as the drylands of South Africa, interspecific competition may be a strong determinant of riverine rabbit distribution.

Accurate monitoring methods are crucial for determining population trends (Lindenmayer et al. 2020), and camera trapping appears to be an efficient method for detecting both riverine rabbits and their competitors. As hares appear to have a significant effect on riverine rabbit occurrence, there is the potential to use the former as a 'surrogate' species
(Caro et al. 2005). Surrogate species are often used in large-scale management, both to represent broad biodiversity and to infer the population status of a closely linked species (Wiens et al. 2008, Tilker et al. 2020). The key characteristic of a surrogate species is conspicuousness, allowing for cost-effective monitoring of cryptic species by conservation authorities. Whilst research on the ecology and distribution of hares in South Africa is lacking, their ubiquity makes them a potentially useful tool in helping researchers to refine landscape-level surveys by focussing on locations lacking hares. Camera trap surveys in South Africa's drylands are increasing (Drouilly et al. 2018a, Woodgate et al. 2018), and these existing surveys could be used to explore the distribution of hares in South Africa, and subsequently test the generality of our findings in this study.

\section{CONCLUSIONS}

Our finding that riverine rabbit occurrence in the SWR is best predicted by hare absence along a gradient of terrain ruggedness contrasts markedly with previous studies. These studies have led to extensive and expensive riverine habitat restoration programs to ensure the long-term survival of the species. Our results suggest these efforts may be misdirected, and that we need a clear and generalizable understanding of the ecological principles that underlie population dynamics and interspecific interactions before making such investments. While we still do not fully understand the drivers of riverine rabbit distribution, our study shows that conservation management has underestimated the importance of competition with other lagomorphs and over-estimated the importance of riverine habitat preservation. We propose that future studies aim to replicate our methodology across the species' range, both at well-established sites that have been used to derive previous distribution models, and at recently discovered new localities (i.e. Touwsrivier and Uniondale).

Acknowledgements. We thank Christy Bragg (of the Endangered Wildlife Trust [EWT]), who was instrumental in conceiving the project. We thank the Sanbona Wildlife Reserve ecologist, Liesl Eichenberger, for granting us permission to conduct this research on the reserve's property and for assistance during fieldwork. We also thank Christopher Rota provided valuable feedback on our data analysis and the 3 anonymous reviewers, who provided commentary on an earlier version of this manuscript. Funding for this project was provided by the Koos and Rona Rupert Opvoedkundige Trust (via EWT). 


\section{LITERATURE CITED}

Adams Z (2014) Distribution and habitat characteristics of the riverine rabbit (Bunolagus monticularis) in close proximity of the Doringrivier within Anysberg Nature Reserve. Research Report, Cape Peninsula University of Technology, Cape Town

Ahlmann V, Collins K, Seal US (2000) Riverine rabbit (Bunolagus monticularis): a population and habitat viability assessment workshop. Conservation breeding specialist group (SSC/IUCN), Apple Valley, MN

Akçakaya HR, Rodrigues AS, Keith DA, Milner-Gulland EJ and others (2020) Assessing ecological function in the context of species recovery. Conserv Biol 34:561-571

Alves PC, Ferrand N, Hackländer K (eds) (2008) Lagomorph biology: evolution, ecology, and conservation. Springer, Berlin

Amarasekare P (2003) Competitive coexistence in spatially structured environments: a synthesis. Ecol Lett 6: 1109-1122

Aunapuu M, Oksanen T (2003) Habitat selection of coexisting competitors: a study of small mustelids in northern Norway. Evol Ecol 17:371392

Araújo MB, Luoto M (2007) The importance of biotic interactions for modelling species distributions under climate change. Glob Ecol Biogeogr 16:743-753

* Arias-Del Razo I, Hernández L, Laundré JW, VelascoVázquez L (2012) The landscape of fear: habitat use by a predator (Canis latrans) and its main prey (Lepus californicus and Sylvilagus audubonii). Can J Zool 90: 683-693

Burgar JM, Burton AC, Fisher JT (2019) The importance of considering multiple interacting species for conservation of species at risk. Conserv Biol 33:709-715

Campbell SP, Clark AC, Crampton LH, Guerry AD and others (2002) An assessment of monitoring efforts in endangered species recovery plans. Ecol Appl 12:674-681

Caravaggi A, Zaccaroni M, Riga F, Schai-Braun SC, Dick JTA, Montgomery WI, Reid N (2016) An invasive-native mammalian species replacement process captured by camera trap survey random encounter models. Remote Sens Ecol Conserv 2:45-58

Caro T, Eadie J, Sit A (2005) Use of substitute species in conservation biology. Conserv Biol 19:1821-1826

Chapman JA, Flux JE (eds) (1990) Rabbits, hares and pikas: status survey and conservation action plan. IUCN, Gland

Chaudhary R, Zehra N, Musavi A, Khan JA (2020) Spatiotemporal partitioning and coexistence between leopard (Panthera pardus fusca) and Asiatic lion (Panthera leo persica) in Gir protected area, Gujarat, India. PLOS ONE 15:e0229045

Coetzee K (1994) The riverine rabbit (Bunolagus monticularis) and its habitat: conservation implications of an unnaturally fragmented distribution. MSc thesis, Saasveld School of Forestry, Port Elizabeth Technikon

Collins K, du Toit JT (2016) Population status and distribution modelling of the Critically Endangered riverine rabbit (Bunolagus monticularis). Afr J Ecol 54:195-206

* Conn PB, Johnson DS, Williams PJ, Melin SR, Hooten MB (2018) A guide to Bayesian model checking for ecologists. Ecol Monogr 88:526-542

Connell JH (1983) On the prevalence and relative importance of interspecific competition: evidence from field experiments. Am Nat 122:661-696
Dee Boersma P, Kareiva P, Fagan WF, Clark AJ, Hoekstra JM (2001) How good are endangered species recovery plans? BioSci 51:643-649

* Devarajan K, Morelli TL, Tenan S (2020) Multi-species occupancy models: review, roadmap, and recommendations. Ecography 43:1612-1624

Didan K, Munoz AB, Huete A (2015) MODIS vegetation index user's guide (MOD13 Series) version 3.00 (Collection 6). Vegetation Index and Phenology Lab, The University of Arizona, Tucson, AZ

* Drouilly M, Clark A, O'Riain MJ (2018a) Multi-species occupancy modelling of mammal and ground bird communities in rangeland in the Karoo: a case for dryland systems globally. Biol Conserv 224:16-25

* Drouilly M, Nattrass N, O'Riain MJ (2018b) Dietary niche relationships among predators on farmland and a protected area. J Wildl Manag 82:507-518

Duthie AG (1989) The ecology of the riverine rabbit Bunolagus monticularis. MSc dissertation, University of Pretoria

* Evans BE, Mosby CE, Mortelliti A (2019) Assessing arrays of multiple trail cameras to detect North American mammals. PLOS ONE 14:e0217543

Farmer H (2006) Lagomorph distribution across Little Karoo vegetation types. Afr J Wildl Res 36:186-188

Fidino M, Simonis JL, Magle SB (2019) A multistate dynamic occupancy model to estimate local colonization-extinction rates and patterns of co-occurrence between two or more interacting species. Methods Ecol Evol 10:233-244

Flux JEC (2008) A review of competition between rabbits (Oryctolagus cuniculus) and hares (Lepus europaeus). In: Alves PC, Ferrand N, Häcklander K (eds) Lagomorph biology: evolution, ecology and conservation. Springer, Berlin, p 241-249

*Gelman A, Hwang J, Vehtari A (2014) Understanding predictive information criteria for Bayesian models. Stat Comput 24:997-1016

*Gerber LR, Hatch LT (2002) Are we recovering? An evaluation of recovery criteria under the U.S. endangered species act. Ecol Appl 12:668-673

* Gould MJ, Gould WR, Cain JW, Roemer GW (2019) Validating the performance of occupancy models for estimating habitat use and predicting the distribution of highlymobile species: a case study using the American black bear. Biol Conserv 234:28-36

*Harrison RL (2019) Temporal niche separation of desert cottontails (Sylvilagus audubonii) and black-tailed jackrabbits (Lepus californicus) in the Chihuahuan Desert. Southwest Nat 63:153-160

*Havstad KM, Gibbens RP, Knorr CA, Murray LW (1999) Long-term influences of shrub removal and lagomorph exclusion on Chihuahuan Desert vegetation dynamics. J Arid Environ 42:155-166

*Hughes GO, Thuiller W, Midgley GF, Collins K (2008) Environmental change hastens the demise of the Critically Endangered riverine rabbit (Bunolagus monticularis). Biol Conserv 141:23-34

* Hulbert IAR, Iason GR, Elston DA, Racey PA (1996) Homerange sizes in a stratified upland landscape of two lagomorphs with different feeding strategies. J Appl Ecol 33: 1479-1488

Kass JM, Tingley MW, Tetsuya T, Koike F (2020) Co-occurrence of invasive and native carnivorans affects occupancy patterns across environmental gradients. Biol Invas 22:22512266 
Kerley GIH (1990) Browsing by Lepus capensis in the Karoo. S Afr J Zool 25:199-200

Ladle A, Steenweg R, Shepherd B, Boyce MS (2018) The role of human outdoor recreation in shaping patterns of grizzly bear-black bear co-occurrence. PLOS ONE 13: e0191730

Larrucea ES, Brussard PF (2009) Diel and seasonal activity patterns of pygmy rabbits (Brachylagus idahoensis). J Mammal 90:1176-1183

Leach K, Montgomery WI, Reid N (2017) Characterizing biotic interactions within the Order Lagomorpha using joint species distribution models at 3 different spatial scales. J Mammal 98:1434-1442

* Lindenmayer D, Woinarski J, Legge S, Southwell D and others (2020) A checklist of attributes for effective monitoring of threatened species and threatened ecosystems. J Environ Manage 262:110312

Lorenzo C, Rioja-paradela TM, Carrillo-reyes A (2015) State of knowledge and conservation of endangered and critically endangered lagomorphs worldwide. Therya 6: 11-30

* Lush L, Ward AI, Wheeler P (2017) Dietary niche partitioning between sympatric brown hares and rabbits. J Zool (Lond) 303:36-45

MacKenzie DI, Nichols JD, Lachman GB, Droege S, Andrew J, Langtimm CA (2002) Estimating site occupancy rates when detection probabilities are less than one. Ecology 83:2248-2255

Marcer A, Sáez L, Molowny-Horas R, Pons X, Pino J (2013) Using species distribution modelling to disentangle realised versus potential distributions for rare species conservation. Biol Conserv 166:221-230

Mayer M, Ullmann W, Heinrich R, Fischer C, Blaum N, Sunde P (2019) Seasonal effects of habitat structure and weather on the habitat selection and home range size of a mammal in agricultural landscapes. Landsc Ecol 34: 2279-2294

Mayer M, Fog Bjerre DH, Sunde P (2020) Better safe than sorry: the response to a simulated predator and unfamiliar scent by the European hare. Ethology 126:704-715

Meredith M, Ridout M, (2016) overlap: estimates of coefficient of overlapping for animal activity patterns. R package version 0.2.3, https://rdrr.io/cran/overlap/

Miller JRB, Pitman RT, Mann GKH, Fuller AK, Balme GA (2018) Lions and leopards coexist without spatial, temporal or demographic effects of interspecific competition. J Anim Ecol 87:1709-1726

Mucina L, Juergens N, Le Roux A, Rutherford MC and others (2006) Succulent Karoo biome. In: Mucina L, Rutherford MC (eds) The vegetation of South Africa, Lesotho and Swaziland. South African National Biodiversity Institute, Pretoria, p 220-299

Nunn N, Puga D (2012) Ruggedness: the blessing of bad geography in Africa. Rev Econ Stat 94:20-36

${ }^{\prime}$ 'Connor KM, Nathan LR, Liberati MR, Tingley MW, Vokoun JC, Rittenhouse TAG (2017) Camera trap arrays improve detection probability of wildlife: investigating study design considerations using an empirical dataset. PLOS ONE 12:e0175684

* Parsons AW, Forrester T, Baker-Whatton MC, McShea WJ and others (2018) Mammal communities are larger and more diverse in moderately developed areas. eLife 7 : e38012

Parsons AW, Rota CT, Forrester T, Baker-Whatton MC and others (2019) Urbanization focuses carnivore activity in remaining natural habitats, increasing species interactions. J Appl Ecol 56:1894-1904

* Probert BL, Litvaitis JA (1996) Behavioral interactions between invading and endemic lagomorphs: implications for conserving a declining species. Biol Conserv 76: 289-295

Qi J, Chehebouni A, Huete AR, Kerr YH, Sorooshian S (1994) Modified soil adjusted vegetation index (MSAVI). Remote Sens Environ 48:119126

R Core Team (2020) R: a language and environment for statistical computing. R Foundation for Statistical Computing, Vienna

Ridout MS, Linkie M (2009) Estimating overlap of daily activity patterns from camera trap data. J Agric Biol Environ Stat 14:322-337

Robinson T, Relton C, Child MF (2016) A conservation assessment of Lepus spp. In: Child MF, Roxburgh L, Do Linh San E, Raimondo D, Davies-Mostert HT (eds) The red list of mammals of South Africa, Swaziland and Lesotho. South African National Biodiversity Institute and Endangered Wildlife Trust, Gauteng

Rossi M, Rembold F, Bolognesi M, Nori M, Mureithi S, Nyberg G (2018) Mapping land enclosures and vegetation cover changes in the surroundings of Kenya's Dadaab refugee camps with very high resolution satellite imagery. Land Degrad Dev 30:253-265

* Rota CT, Ferreira MAR, Kays RW, Forrester TD and others (2016) A multispecies occupancy model for two or more interacting species. Methods Ecol Evol 7:1164-1173

* Rouco C, Barrio IC, Cirilli F, Tortosa FS, Villafuerte R (2019) Supplementary food reduces home ranges of European wild rabbits in an intensive agricultural landscape. Mamm Biol 95:35-40

Scharine PD, Nielsen CK, Schauber EM, Rubert L, Crawford JC (2011) Occupancy, detection, and habitat associations of sympatric lagomorphs in early-successional bottomland forests. J Mammal 92:880-890

Smith AT, Johnston CH, Alves PC, Hackländer K (eds) (2018) Lagomorphs: pikas, rabbits, and hares of the world. Johns Hopkins University Press, Baltimore, MD

Smith RK, Jennings NV, Harris S (2005) A quantitative analysis of the abundance and demography of European hares Lepus europaeus in relation to habitat type, intensity of agriculture and climate. Mammal Rev 35:1-24

Stan Development Team (2020) RStan: the R interface to Stan. R package version 0.21 .2

Stott P (2003) Use of space by sympatric European hares (Lepus europaeus) and European rabbits (Oryctolagus cuniculus) in Australia. Mamm Biol 68:317-327

* Swanepoel P (2019) Spatial and feeding ecology of elephants (Loxodonta africana) on Sanbona Wildlife Reserve, Little Karoo, South Africa. MSc thesis, University of Stellenbosch. Available at https://scholar.sun.ac.za/ handle/10019.1/106140

Tilker A, Nguyen A, Abrams JF, Bhagwat T and others (2020) A little-known endemic caught in the South-east Asian extinction crisis: the Annamite striped rabbit Nesolagus timminsi. Oryx 54:178-187

Tobler MW (2014) Camera base version 1.6.1. Botanical Research Institute of Texas, Fort Worth, TX

Tobler MW, Kéry M, Hui FKC, Guillera-Arroita G, Knaus P, Sattler T (2019) Joint species distribution models with species correlations and imperfect detection. Ecology 100:e02754 
Valiente-Banuet A, Verdú M (2008) Temporal shifts from facilitation to competition occur between closely related taxa. J Ecol 96:489-494

Wiens JA, Hayward GD, Holthausen RS, Wisdom MJ (2008) Using surrogate species and groups for conservation planning and management. BioScience 58:241-252

Weterings MJA, Ewert SP, Peereboom JN, Kuipers HJ and others (2019) Implications of shared predation for space

Editorial responsibility: Abi Tamim Vanak, Bangalore, India

Reviewed by: 3 anonymous referees use in two sympatric leporids. Ecol Evol 9:3457-3469

* Wilson MFJ, O'Connell B, Brown C, Guinan JC, Grehan AJ (2007) Multiscale terrain analysis of multibeam bathymetry data for habitat mapping on the continental slope. Mar Geod 30:3-35

* Woodgate Z, Distiller G, O'Riain J (2018) Variation in mammal species richness and relative abundance in the Karoo. Afr J Range Forage Sci 35:325-334

Submitted: October 26, 2020

Accepted: December 18, 2020

Proofs received from author(s): March 16, 2021 